\title{
A Brief Analysis on the Problems and Measures of NGO's Participation in Public Crisis Management
}

\author{
Li Linghua \\ Department of Marxism \\ Yunnan University of Finance and Economics, \\ P. R. China, \\ (604227454@qq.com)
}

\begin{abstract}
At present, China's public crisis is more serious than before. The traditional public crisis management thinking is difficult to adapt to the needs of the development of the new situation. This paper based on the governance theory .Public crisis management may be defined as a kind of management in the field of the whole society .In light of governance theory, trying to build a path for NGOs and other social subjects to take part in public crisis management. This paper argues that, in order to realize "good governance" of public crisis management, must clarify the role of government and NGO. Promote the healthy development of NGO. Improve the NGO participation in public crisis management system, mechanism and legal system, improve NGO participation in public crisis management of the quality and ability.
\end{abstract}

Keywords-Public crisis; Crisis management; Governance; the government; $N G O$

\section{INTRODUCTION}

At present, China is in the key period of social transformation, the public crisis situation is serious. Governments at all levels must take seriously the public crisis management. Government as the main body of traditional public administration, although afford the main management responsibility in the crisis management, in front of the complex public crisis, the government will also appear to some extent ability insufficiency, the reacting condition. But in the face of the public crisis complex, the government will also appear to some extent ability insufficiency, the reacting condition. Therefore, calling for social forces to participate in public crisis management is the inevitable trend. Based on the above background, this paper trying to explore the reality value of NGO participation in public crisis management, in order to realize "good governance" of public crisis management.

\section{THEORY ANALYSIS OF THE NGO PARTICIPATION In PUblic CRisis MANAgEMENT}

Public crisis is a sudden event. It can threat people's daily life, work, property and life. Scholars believe that, "Public crisis happened suddenly, has significant impact for the organization's survival and development, managers need rapid response after the crisis"[1] P15. Public crisis management is refers to the government or other public management through the establishment of effective public crisis early warning and response mechanism, and the quantitative and effective measures to prevent and dissolve the public crisis, to restore social order of normal production and life, to restore social stability and security of People's Daily living environment, promote social stability and development [2].

NGO, English full name is the Non-Governmental Organization (NGO). In the official documents of China and scholars in research reports are generally called folk organization. The United Nations on the NGO is defined as NGO, refers to the civil organization profit at the local, national or international level organized, non voluntary. Salamon believes that NGO has the characteristics of organization, private, non-profit, autonomous, voluntary attribute. [3]P3

Governance theory provide theoretical basis for $\mathrm{NGO}$ participating in crisis management. Global governance association hold the view that governance is the sum of individuals and institutions, official and private management of their common affairs, Various conflicting interests can come together by taking the chance and find a way to cooperate. It is a continuous process, which can may be either opposite or different from each other to adapt to the interests of in this process, also can take cooperative action. It not only includes formal institutions and system to ensure people obey, also informal arrangements that people agree or accept their interests. The main character of governance theory: Self-regulating manner; various actors; interactive process; nation's leading role. Good governance is to maximize the benefits of public social management process, which is a good governance and mainly refers to good governance can gain performance, they reflected in the governance of political effect, management effectiveness, economic and social effects aspects[4] P214. Governance Theory and its implications NGO participation in public crisis management is: public crisis management is a whole social sphere administration. Although the government has undertaken a leading role, also should encourage and support NGO participation in public affairs, crisis management and provide effective channels of participation and public resources, give full play to its role. 


\section{PROBlems of NGO PARTICIPATION IN PUBliC CRISIS MANAGEMENT}

\section{A. Weak development of $N G O$}

The direction of China's social development is making more use of NGO, the government should give NGO more chances to dispose things. But in China, due to the strictness of the political development, the development of NGO is lack of loose external environment, on the other hand Chinese citizens has not fully trust in NGO's operating mode and the system, therefore the development of the NGO has been blocked [5]P286. On the one hand there are too much registered limits of $\mathrm{NGO}$, On the other hand, the social organizations and private non-enterprise organizations are in the charge of registration administration organ and the management system of competent authorities of the business. This situation , making it hard under the necessary legal policy regulation and supervision, for various forms of NGO in China as a whole and it is difficult to enjoy the necessary support and preferential treatment from government in the financial and tax departments, besides, it is hard to mobilize a lot of social resources, to play a big role in the social life, to get legitimate identity from the whole social members generally, and thus restrict the NGO's own development space, its viability is extremely fragile.

\section{B. The inappropriate cooperation mechanism between the $N G O$ and the government in public crisis management}

China has had a long history of "powerful government", the government lack of awareness that the NGO participation in public crisis management over longer period of time, and there are faults exists in the governance, both failed to establish and improve communication and coordination mechanism[6] P167. In public crisis management, the government is always the core, aiming at unified scheduling and coordinating of all. NGO should be aimed at the duty of related areas to assist the government work, obey the scheduling and arrangement of the government. However, because the government has not fully provide external social space that NGO healthily develop need, so the government has a feeling of strangeness on the management orientation , failing to communicate with each other, and only convey its decisions in the form of administrative command usually, without establishing the normal communication and coordination mechanism. When facing the public crisis, the government often lack for consciousness of permitting NGO to participate in the crisis management, also the NGO don't know how to cooperate with the government crisis management. On account of the lack of a clear division of management labor, there may be a partial function overlapping phenomenon, failing to avoid a waste of resources in crisis management. At the same time, because of a lack of normal coordination mechanism between $\mathrm{NGO}$, it is often difficult to get government help in crisis management integration, command and synergy, resulting in low efficiency and scattered force.

\section{NGO are not equipped to cope with public crisis}

At present, China's NGO are at an early stage of development, the lower specialized service level and their weaker ability are important factors that restrict their participation in public crisis management. Some NGO are lack of high-quality talent, the articles of association management and self-discipline, so their daily management is more extensive, and there are few NGO which really able to adapt to the market environment and can make full use of social resources. In public crisis management, the NGO should have technical and professional ability, including setting the organizational structure of the response to public crisis, the establishment of management and operation mechanism, the integration of social resources, the excavation of specialized resources, the shaping of their own image and so on various aspects ability, also they should have the oversight of NGO themselves and self -assessment when deal with public crisis, but their performance is obviously insufficient, the lack of these abilities affected their role in crisis management [7].

\section{The law for NGO participating in public crisis management needs to be improved.}

At present, although China has established emergency management system of laws and regulations which are on the basis of the Constitution, with the Emergency Response Law as the core, and supporting by relevant individual laws and regulations, there are still no specific legal provisions to regulate and restrict NGO how to participate in public crisis management, such as the scope of participation, the authority issues, the use of public resources, and how to protect the interests of their own etc. Because the NGO's legitimacy is not yet clear, its action ability is very limited [8]P69. There must be a good legal environment for Chinese NGO to participate and play a proper role in public crisis management. Based on the laws they can establish their honesty and reputation, and solve other issues such as the transparency in operation, the financial sustainability, the participation legitimacy and negligence penalty etc. Yet the relevant laws and regulations still need to be improved.

\section{THE PATHS FOR NGO PARTICIPATING in Public Crisis Management}

\section{A. Actively foster and develop NGO}

The template is designed so that author affiliations are not repeated each time for multiple authors of the same affiliation. Please keep your affiliations as succinct as possible (for example, do not differentiate among departments of the same organization). This template was designed for two affiliations.

1) Reform NGO registration and approval system and dual management system, and reduce the access standard.

Unify the registration licensing and regulatory functions which currently scattered in different Government Systems and People's organizations. Establish a unified regulatory body to unify the record, registration and supervision functions of NGO. Through the reform of the existing NGO registration and approval system and dual management system, to maximally broadened the admission categories for NGO, and solve the problem of legitimacy of them with Zero Thresholds, and create a better institutional environment through policy guidance for the development of nonprofit NGO [2]. 
B. Rationalize the system mechanism of NGO participation in public crisis management.

1) Position the role of the government and NGOs in public crisis management reasonably.

In public crisis management, the role of the Government will shift from all social affairs "as a guiding person" and a hands-on "oarsman" to planning, guidance and "helmsman". Relationship between government and NGO shift also from executive and obedience to actively cooperate, interaction and cooperation, interdependent partnerships. [10]P353-354 First, the government should take the initiative to open to NGO information, consultation, explaining the various emergency management policies and identify and resolve problems in emergency management; NGO also provide information and resources to support the Government to promote the implementation of crisis management policy. Secondly, we must give full play to NGO's the role of self-service, self-regulation and self-help in public crisis management, and take shape a interactive, network operations structure(between the government and the $\mathrm{NGO}$, among the various NGO, between NGO and citizen), to achieve the government, market, social functional complementation.

2) Specify the duties demarcation of the government and NGOs in public crisis management.

On crisis management objectives, the main goal of the government is to protect the lives and property of citizens, maintain social order and safeguard national security, non-proliferation seeks crisis, not to aggravate, not seriously affect the sound development of the national economy and society; And the main goal of NGO is to participate in the treatment of crisis by personnel dispatch, means material assistance and psychological assistance to raise funds, and safeguard the fundamental rights of the affected population in crisis, the fundamental rights of especially vulnerable groups, as well as related professional services of aid. In the area of crisis management, the government should responsible for the region's crisis management, but also with higher levels of government and the vicinity of the government is doing a good job at a higher level or the adjacent area of crisis management; and NGOs are relatively flexible, it can be according to their own network, policy, resources independently delineated area management.

3) Establish the responsibility supervision mechanism for the government and NGOs in public crisis management.

On the one hand, we need to work quickly to public crisis management establishment and perfecting of related laws and regulations, clear the government and NGO in the public crisis management in the relevant legal responsibility; On the other hand the government should also stepped up efforts to improve the emergency plans at all levels of public crisis management, in-depth analysis of each link, each step of responsibility by the government and NGO. Meanwhile, the government and the NGO establish mutual supervision, jointly promote of monitoring mechanisms, through government oversight to regulate NGO behavior in crisis management, and to promote the government's crisis management performance through civilian oversight of NGO. [5]

\section{Improve the ability to deal with public crises of NGO.}

1) Improve specialized qualities to disposal of public crises of $N G O$.

Through aiming at the features of public crisis management and incorporating the organizations' service areas, the trainings of public crisis management should be strengthened by the organizations to their members. This can enable them to master the knowledge such as organization operating system in confronting the public crisis. Communications and connections with the government, enterprises and non-governmental organizations should be largely strengthened so as to win policy support from the government and obtain financial support from enterprises and moral support from the society while dealing with the crisis. We should strengthen HR construction of NGOs, resort to devised programs to attract top-quality volunteers, and to make up for HR inadequacy including public crisis management talents. We also should give full play to the ability to infiltrate NGO community in its own field, instilling risk management "sooner" thinking, improving their early warning capacity, the potential to resolve the crisis in the bud.

2) Establish internal crisis management system of NGO.

According to the practice of public crisis management, establish a series of related systems, including: setting up relief organization, command system, working process, and the regulation of rewards and punishments to rational utilization of NGO and community disaster relief; Through their own information network contact related professionals into a line of disaster relief; Contact related folk charity groups to participate in disaster relief work, alliance with other

NGO groups such as disaster relief; Assist the civil affairs at the grass-roots level of service team with own organization system, research demand of victims effectively, and establish the channels of distribution of resources and so on. [11]P22-23 At the same time, to build the organization's crisis management evaluation system, discovering the problems existing in the existing crisis management system, strengthening the prevention of crisis and the ability to cope with the crisis.

\section{Improve the law environment for $N G O$ participation in public crisis management.}

Crisis as a state of emergency, can cause huge impact on economies and societies, and the extreme expansion of power in a state of emergency is likely to be even deviate from the rule of law is the basic way. Therefore, we must continue to improve China's legal system of state of emergency, regard the law of public crisis management system as an open system of the rule of law, amend, improve and coordinate with the public crisis management related laws, regulations and relevant provisions of the legal system, make it to each other and keep the emergency response law coordinated, maintain the unity of the legal system of public crisis management and coordination. To enrich the content of the NGO participation in public crisis management of relevant laws, to ensure that the NGO participation in public crisis management, there are laws by relevant laws and regulations to regulate the behavior of NGO of crisis management, improve the management efficiency, protect their legitimate rights and interests. At the 
same time, we must continue to improve our system of emergency plans, took the role of NGO in crisis management include, clarify its legal status, the provisions of the relevant responsibilities, determine its administrative authority, regulating the behavior of its emergency, for their participation in public crisis management to provide a good environment for the rule of law.

\section{CONCLUSION}

Public crisis management under the perspective of governance theory must be the management in the field of whole society. Government played a dominant role in this management, at the same time, the role of NGO should also be noticed and stimulated. In public crisis management, the government must break through the traditional administrative imperative one dimensional thinking, actively construct the partnership between the government and NGO, to promote actively cooperate with each other, mutual cooperation, mutual dependence, with maximum efficiency, maximize the public interest of the whole society. In order to realize "good governance" of public crisis management, must clarify the role of government and NGO, increase the fiscal and taxation support of NGO development, promoting the healthy growth of the NGO; We must rationalize NGO participation in public crisis management system, the system and the legal system, clarify the responsibilities of government and NGO in public crisis management, establish the responsibility of the government and NGO in the public crisis management and supervision mechanism, improve the rule of law environment of NGO participation in public crisis management; NGO must strengthen self construction, enhance the ability of NGO to deal with the public crisis, cooperate with the government public crisis governance to achieve goals.

\section{REFERENCES}

[1] Wang Yukai, public crisis and management personnel China [M]. press, 2006

[2] Niu Cong. Non governmental organizations to participate in public crisis management problems of [D]. master thesis. Dalian: Dongbei University of Finance and Economics.2014

[3] Lester M. Salamon. Jia Xijin, Wei Yu, et al. Global civil society non profit sector horizon [M]. Social Sciences Academic Press, 2002.

[4] guang-bin Yang Ed. An introduction to political science (fourth edition) [M]. Beijing: renmin university of China publishing house, 2011 edition.

[5] XiaoSiXuan. The plight of Chinese non-profit organizations to participate in public crisis management and way out [J]. Journal of management, 2015 (25)

[6] JingZhiGong,XuZheng-hua. Non-governmental organizations to participate in public crisis management research in China [J]. Journal of cooperation in economy and technology, 2015 (10).

[7] Wang Yingqiao. Non-governmental organizations to participate in public crisis management research [D]. Master's degree thesis. Shanghai: Shanghai normal university. 2015.

[8] Han Junkui.Study on NGO involved in the wenchuan earthquake emergency rescue $[\mathrm{M}]$. Beijing, Beijing university publisher, 2009

[9] Wang Chenhe. Study on non governmental organizations in public crisis governance from the perspective of good governance [D]. master thesis. Wuhan: Huazhong Normal University,2015.

[10] Guo Ji,Gao Xiaoping, Jin Jianghao. The government emergency management practice [M]. Beijing: Central Party School Press, 2004

[11] Lan Xue, Zhang Qiang, Zhong Kaibin. Crisis management [M]. Beijing: Tsinghua University press, 2003.) 